\title{
Data assimilation experiment of precipitable water vapor observed by a hyper-dense GNSS receiver network using a nested NHM-LETKF system
}

\author{
Masanori Oigawa ${ }^{1,2^{*}}$, Toshitaka Tsuda $^{1,3}$, Hiromu Seko ${ }^{4}$, Yoshinori Shoji ${ }^{4}$ and Eugenio Realini ${ }^{1,5}$
}

\begin{abstract}
We studied the assimilation of high-resolution precipitable water vapor (PWV) data derived from a hyper-dense global navigation satellite system network around Uji city, Kyoto, Japan, which had a mean inter-station distance of about $1.7 \mathrm{~km}$. We focused on a heavy rainfall event that occurred on August 13-14, 2012, around Uji city. We employed a local ensemble transform Kalman filter as the data assimilation method. The inhomogeneity of the observed PWV increased on a scale of less than $10 \mathrm{~km}$ in advance of the actual rainfall detected by the rain gauge. Zenith wet delay data observed by the Uji network showed that the characteristic length scale of water vapor distribution during the rainfall ranged from 1.9 to $3.5 \mathrm{~km}$. It is suggested that the assimilation of PWV data with high horizontal resolution (a few $\mathrm{km}$ ) improves the forecast accuracy. We conducted the assimilation experiment of high-resolution PWV data, using both small horizontal localization radii and a conventional horizontal localization radius. We repeated the sensitivity experiment, changing the mean horizontal spacing of the PWV data from 1.7 to $8.0 \mathrm{~km}$. When the horizontal spacing of assimilated PWV data was decreased from 8.0 to $3.5 \mathrm{~km}$, the accuracy of the simulated hourly rainfall amount worsened in the experiment that used the conventional localization radius for the assimilation of PWV. In contrast, the accuracy of hourly rainfall amounts improved when we applied small horizontal localization radii. In the experiment that used the small horizontal localization radii, the accuracy of the hourly rainfall amount was most improved when the horizontal resolution of the assimilated PWV data was $3.5 \mathrm{~km}$. The optimum spatial resolution of PWV data was related to the characteristic length scale of water vapor variability.
\end{abstract}

Keywords: Precipitable water vapor, Dense GNSS receiver network, Data assimilation

\section{Background}

Low-level moisture in the troposphere is essential for the initiation and development of deep moist convection. Kuo et al. (1993) assimilated precipitable water vapor (PWV) data observed by radiosonde into a mesoscale numerical model by relaxing the predicted PWV toward the observed PWV. They reported that assimilation of PWV improved accuracy of short-range precipitation forecast. Guo et al. (2000) assimilated PWV data detected

\footnotetext{
*Correspondence: masanori.oigawa@gmail.com

${ }^{1}$ Research Institute for Sustainable Humanosphere (RISH), Kyoto

University, Gokasho, Uji, Kyoto 611-0011, Japan

Full list of author information is available at the end of the article
}

by the global navigation satellite system (GNSS) by using a four-dimensional variational assimilation system and succeeded in reproducing the observed precipitation pattern associated with a squall line. The Geospatial Information Authority of Japan (GSI) operates a nationwide GNSS observation network called GNSS Earth Observation NETwork (GEONET), which contains a mean interstation distance of about $20 \mathrm{~km}$ over Japan. Assimilation experiments of GEONET-PWV were performed using four-dimensional variational assimilation systems (Seko et al. 2004; Kawabata et al. 2007; Shoji et al. 2009). Yan et al. (2009) performed assimilation of GNSS-derived zenith tropospheric delay (ZTD) data, that is, atmospheric delay above the receiver, observed by a dense 
GNSS network during the Convective and Orographically-induced Precipitation Study (COPS) campaign, where the shortest distance between the assimilated ZTD was longer than $10 \mathrm{~km}$. They reported improvement in forecasts during weak precipitation but reduced accuracy in heavy precipitation. Kawabata et al. (2013) conducted an assimilation experiment of GEONET-derived slant path delay (SPD) data, that is, the atmospheric delay along the ray path of a GNSS radio signal, and succeeded in reproducing the heavy rainfall event that occurred over Okinawa Island in August 19, 2009.

Although many assimilation studies of GNSS-derived water vapor data with variational assimilation systems have been conducted so far, there have been few studies that assimilated PWV using an ensemble Kalman filter (EnKF; Evensen 1994) system. Seko et al. (2011) conducted an assimilation experiment of GEONET-derived PWV by using a local ensemble transform Kalman filter (LETKF; Hunt et al. 2007) method based on the Japan Meteorological Agency Non-Hydrostatic Model (JMANHM; Saito et al. 2007). Seko et al. (2013) developed a two-way nested NHM-LETKF system and investigated the synergistic effects of simultaneous assimilation of the Doppler radar radial wind velocity and water vapor data observed by GEONET (i.e., PWV and slant water vapor (SWV) that is the accumulated water vapor amount along the ray path of a GNSS radio signal). They succeeded in increasing the number of ensemble forecasts that reproduced localized heavy rainfall by assimilating the GNSS data and the Doppler radar data.

The EnKF is a state estimation technique based on a Monte Carlo method. The EnKF uses short-term ensemble forecasting to estimate flow-dependent background error covariance, assuming each ensemble member result is a statistical sample. However, generic EnKF studies use up to 100 ensemble members partially due to limited computational resources. This limited ensemble size in EnKF introduces sampling errors into the background error covariance and deteriorates the accuracy of analysis ensemble. To address this problem, the covariance localization method has been used to remove spurious error correlations between distant locations (Houtekamer and Mitchell 1998; Hamil et al. 2001). In recent years, some assimilation studies applied multiple localization scales. Zhang et al. (2009) applied a small localization scale to high-resolution Doppler radar observation data and a large localization scale to synoptic scale radiosonde observation data. Miyoshi and Kondo (2013) applied a multi-scale localization approach by changing the localization scale, depending on the scales of error correlations, and reported promising results.
Oigawa et al. (2014) simulated large PWV fluctuations at the local scale less than $10 \mathrm{~km}$ during heavy rainfall. Aonashi (2008) reported that the horizontal scale of background error correlations in a precipitating region is smaller than that in a non-precipitating region. These earlier studies suggest that a smaller horizontal localization radius should be used to assimilate PWV data over a precipitating region. However, as far as the authors know, there has been no study that assimilated PWV data with a horizontal resolution less than $10 \mathrm{~km}$, using a small horizontal localization radius for PWV data over a precipitating region.

The objective of this study is to investigate the assimilation effects of the high-resolution PWV data derived from a hyper-dense GNSS receiver network in an effort to improve the simulation accuracy of heavy rainfall. Here we use a two-way nested NHM-LETKF system and apply it for a heavy rainfall event over Uji, Kyoto, Japan, in August 14, 2012. Figure 1 shows the hyper-dense GNSS receiver network with a mean inter-station distance of $1.7 \mathrm{~km}$ near the Uji campus of Kyoto University (Sato et al. 2013), hereafter called the Uji network. Horizontal resolution of the retrieved PWV derived from the Uji network was improved by estimating the PWV from a slant delay at the highest elevation angle. Large horizontal inhomogeneities of PWV, even at the local scale less than $10 \mathrm{~km}$, have been observed by the Uji network in periods of heavy rainfall over the Uji network. Considering the difference in the characteristic length scale of PWV fluctuations between precipitating regions and non-precipitating regions, we applied multiple horizontal localization radii, scales of which depend on precipitation intensity. We also investigated the optimum interstation distance of GNSS receivers for reproducing heavy rainfall by thinning out PWV data at several stations in the Uji network.

The structure of this paper is as follows. First, the heavy rainfall event on August 14, 2012, and the associated PWV variations observed by the Uji network are described. Second, the design of the data assimilation system and the assimilation method of PWV are explained. Next, results of the data assimilation experiment using high-resolution PWV data are described. Finally, a summary and discussion are presented.

\section{Heavy rainfall event on August 13-14, 2012, in Uji, Kyoto, Japan}

We focused on the heavy rainfall event occurring on August 13-14, 2012, in Uji, Kyoto (called "Uji heavy rainfall" hereinafter). The Uji heavy rainfall is considered the most devastating event to take place during the observation period of the Uji network between 2010 and 2015. In 


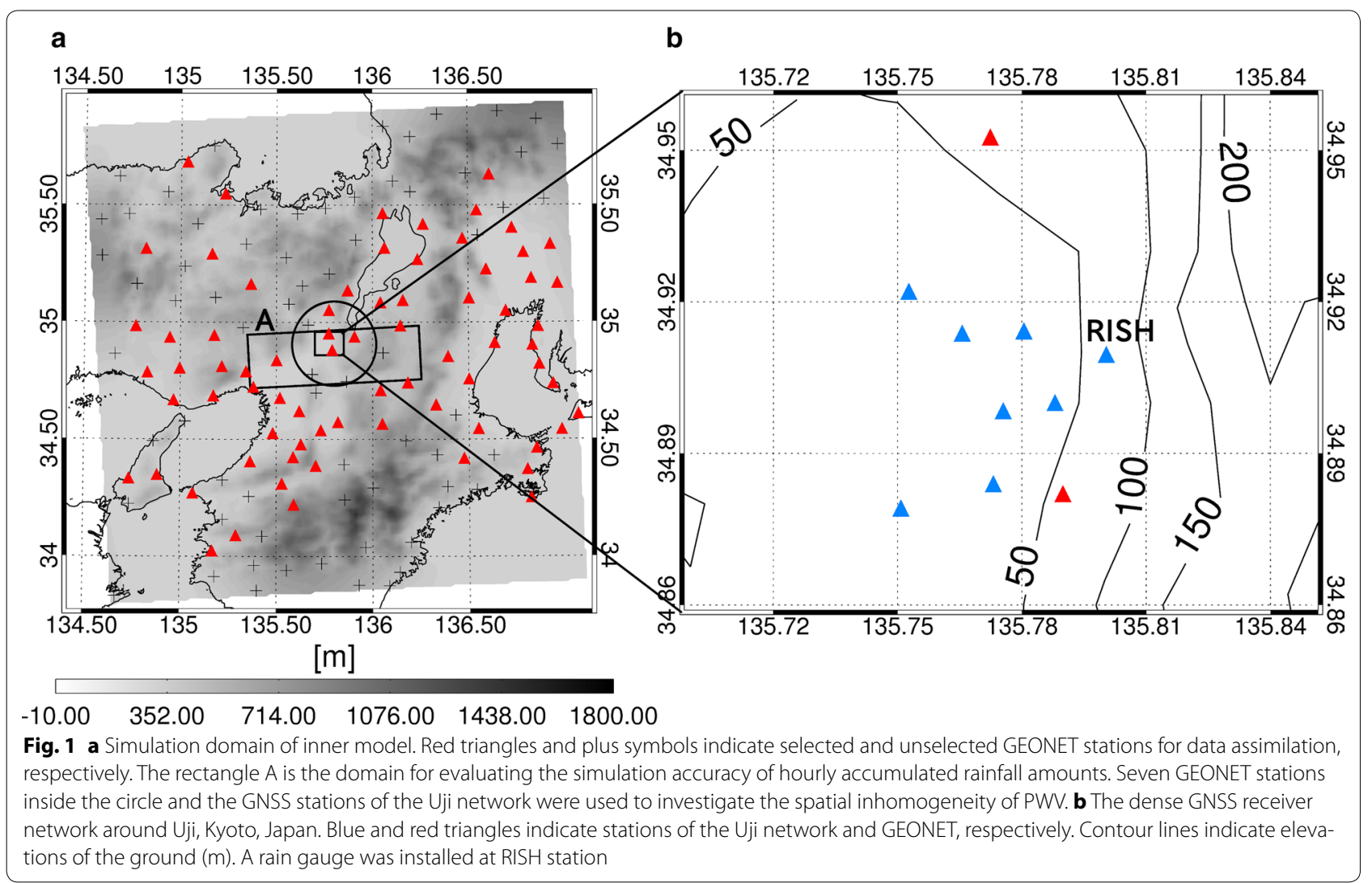

this event, two people were killed and 2275 houses were damaged due to stationary back-building-type convective systems. Figure 2 shows the hourly rainfall derived from precipitation data observed by the radar network of the Japan Meteorological Agency (JMA). Mesoscale convective systems (MCSs) were stationary over the Uji network from 2100 local time (LT) on August 13 to 0600 LT on August 14. Ishihara and Takara (2013) reported that the nature of the MCSs over the Uji network changed with time. The MCS before 0000 LT on the 14th was a backbuilding type. After a weak rain period during 0000-0200 LT on the 14th, a back-building-type MCS was formed again during 0200-0500 LT. The MCS changed into a squall line after $0500 \mathrm{LT}$ on the 14th. As shown in Fig. 2, the MCS became active after $0300 \mathrm{LT}$, and the precipitating region started to move southward after $0500 \mathrm{LT}$ as the MCS was transformed into a squall line. The accumulated precipitation was $322 \mathrm{~mm}$, accumulated over $10 \mathrm{~h}$ until $0600 \mathrm{LT}$ on the 14th, measured at the building of Research Institute for Sustainable Humanosphere (RISH). The heavy rainfall at RISH was brought by convective clouds that were continuously generated one after another west of the Uji network. During the heavy rainfall event, the Uji network was located at the northern edge of the MCSs.

\section{GNSS-derived PWV observed by the Uji network}

In the conventional GNSS meteorology technique, the delays from all available GNSS satellites above an elevation angle of $5^{\circ}-10^{\circ}$ are averaged to arrive at a singlevalue estimate for PWV. As a result, GNSS-derived PWV is estimated as a spatially averaged water vapor amount within an inverse cone defined by the elevation cutoff angle, resulting in smoothed local-scale PWV fluctuations. Sato et al. (2013) succeeded in improving the horizontal resolution of PWV derived from the Uji network, estimating PWV from a single slant delay at the highest elevation angle. High horizontal resolution PWV data retrieved by this method are called PWV $\mathrm{SPD}_{\mathrm{H}}$, hereinafter. When we retrieved PWV $\mathrm{SPD}_{\mathrm{SP}}$, we projected the slant delay at the highest elevation angle onto the zenith direction by using the global mapping function (GMF) (Böhm et al. 2006). We also retrieved PWV data by the conventional GNSS meteorology technique by using a low elevation angle cutoff of $10^{\circ}$, which is called "PWV $\mathrm{CON}_{\mathrm{C}}$ ", hereinafter. Details about the strategy of the GNSS analysis used in this study are described in Appendix. The satellite constellation of the Quasi-Zenith Satellite System (QZSS) is preferable for retrieving $\mathrm{PWV}_{\mathrm{SPD}-\mathrm{H}}$ because the QZSS provides at least one satellite continuously close to the zenith over Japan. The errors of PWV $\mathrm{V}_{\text {SPD-H }}$ 

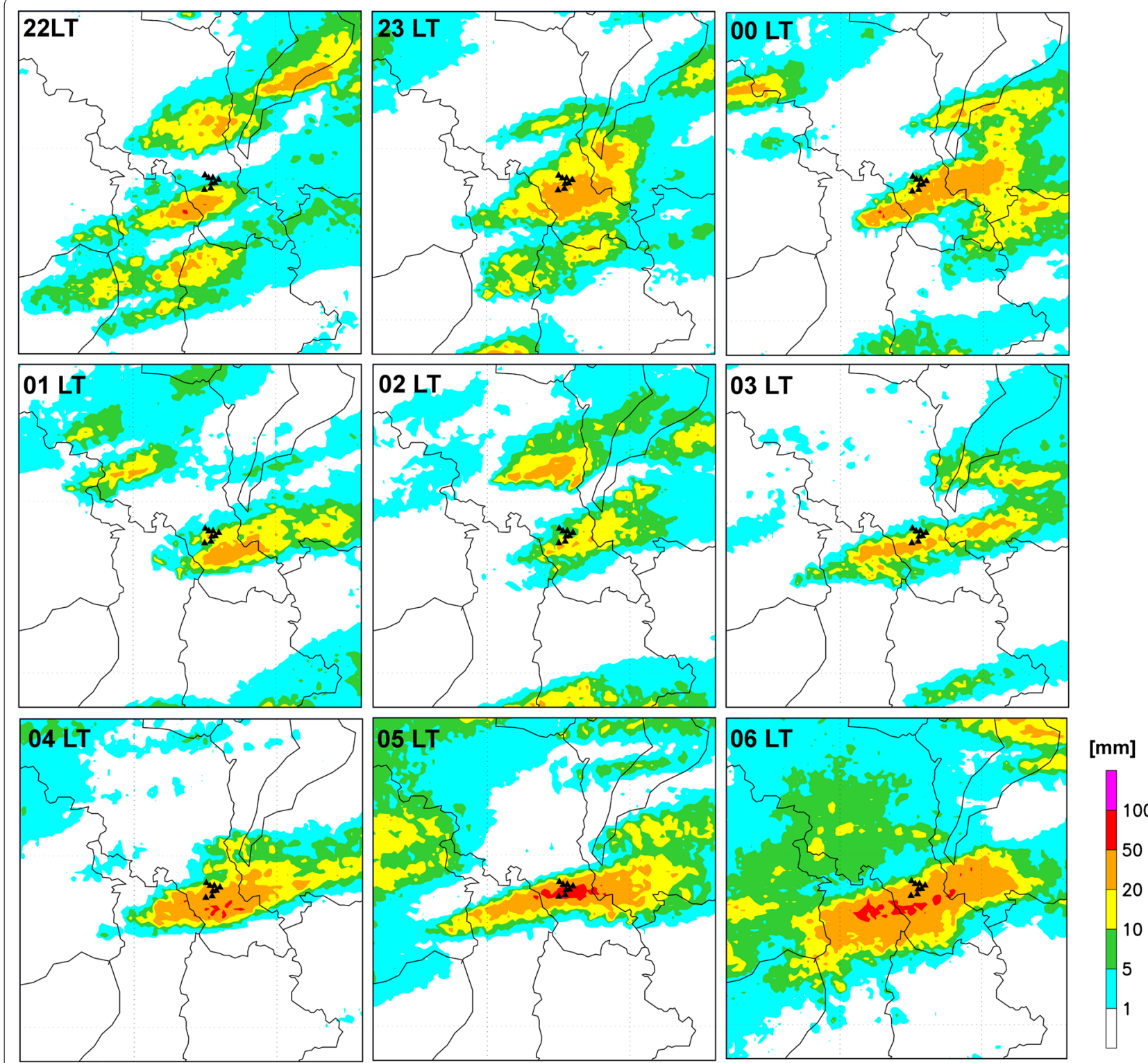

Fig. 2 Maps of hourly accumulated rainfall from 2200 LT on August 13, 2012, to 0600 LT on August 14, 2012, derived from radar data of JMA. Triangles indicate stations of the Uji network

due to the variable geometry of satellite-receiver line of sights during heavy rainfall could be reduced by about $20 \%$ if PWV $\mathrm{SPD}-\mathrm{H}_{\mathrm{i}}$ is retrieved by using the QZSS satellite at the highest elevation instead of using the GPS satellite at the highest elevation (Oigawa et al. 2014). During the Uji heavy rainfall event, the QZSS satellite did not exist close to the zenith. Therefore, the GPS satellites above $60^{\circ}$ elevation angle were used to estimate PWV $\mathrm{SPD}-\mathrm{H}_{\text {. }}$

Figure 3a indicates the time variation of the 10-min rainfall observed by a rain gauge at RISH. To investigate the degree of the spatial inhomogeneity of PWV around the Uji network, we calculated the root-mean-square (RMS) values of PWV using the GNSS data observed by 15 GNSS stations around Uji, i.e., seven GEONET stations inside the circle in Fig. 1a and eight GNSS stations of the Uji network. The RMS values were calculated every $2 \mathrm{~km}$,

$$
\operatorname{RMS}(2(i-1) \leq r<2 i)=\sqrt{\frac{1}{n(i)} \sum_{j=1}^{n(i)}\left(\mathrm{dPWV}_{j}\right)^{2}}
$$


where $n$ is the total number of combinations of any two GNSS stations inside the circle. The inter-station distance $(r)$ is greater than or equal to $2(i-1) \mathrm{km}$ and smaller than $2 i \mathrm{~km}$, where $i$ varies from 1 to 12 . Variable dPWV is the difference in PWV between two GNSS stations. During 0300-0600 LT on August 14 when the MCS became active, RMS values of $\mathrm{PWV}_{\mathrm{CON}}$ and $\mathrm{PWV}$ SPD-H also became large. Precipitation intensity at RISH became strong after $0240 \mathrm{LT}$. RMS of PWV $\mathrm{VPD}_{\mathrm{SP}}$ became strong after $0140 \mathrm{LT}$ at a horizontal scale between 5 and $10 \mathrm{~km}$,

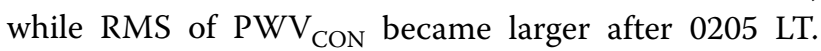
In addition, RMS values of $\mathrm{PWV}_{\mathrm{CON}}$ and $\mathrm{PWV}$ SPD-H achieved maximum values, preceding the peak time of the surface rainfall at RISH. Oigawa et al. (2015) analyzed a $250-\mathrm{m}$ mesh model data simulated by JMA-NHM that successfully simulated the observed rapid increase in PWV prior to surface rainfall during the Uji heavy rainfall event. It was found that in the model, the local PWV maximum began to form about 16 min before the surface rainfall due to wind convergence near the ground. Based on the earlier study, it can be inferred that the RMS of PWV, i.e., horizontal inhomogeneity of PWV, became large because the local PWV maximum formed by wind convergence near the ground was detected by the $\mathrm{Uji}$ network. The RMS of PWV $\mathrm{CON}_{\text {and }}$ PWV $\mathrm{SPD}_{\mathrm{SP}}$ was especially large for a mean inter-station distance between 5 and $10 \mathrm{~km}$ (Fig. 3b), suggesting that the GNSS receiver network with spatial separation denser than GEONET is

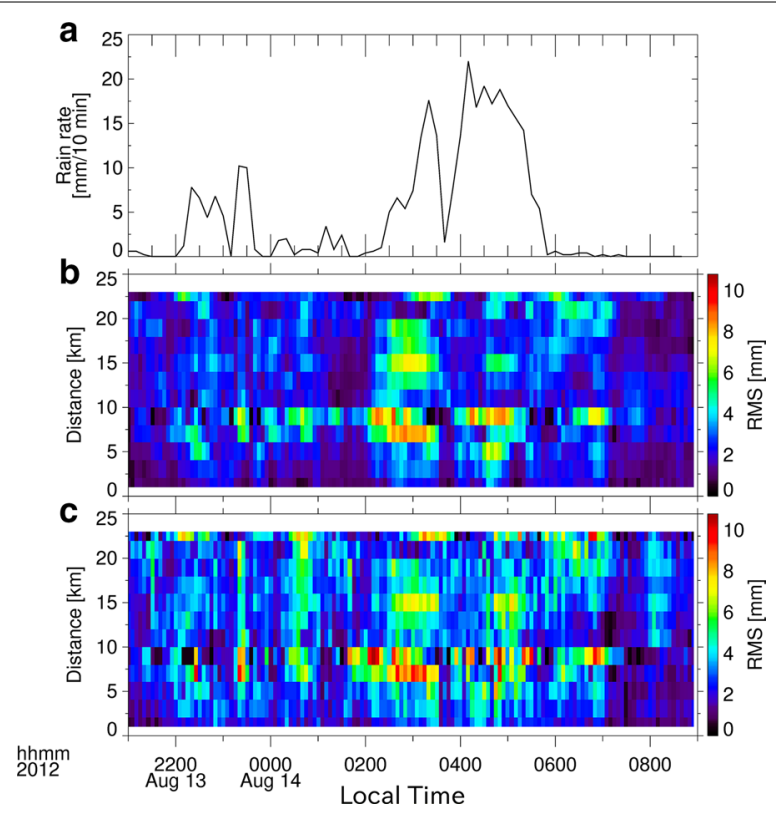

Fig. 3 a Time variation of 10-min rainfall observed by a rain gauge installed at RISH. b Time-distance variations of RMS of PWV $\mathrm{CON}_{\text {CN }}$ around $\mathrm{Uji}$. c Time-distance variations of RMS difference of PWV $\mathrm{V}_{\text {SPD-H }}$ around Uji useful for observing the variations in water vapor associated with convective precipitation. Figure $3 \mathrm{~b}$ and $\mathrm{c}$ shows that the RMS values of PWV $\mathrm{VPD}_{\mathrm{SP}-\mathrm{H}}$ were larger than those of $\mathrm{PWV}_{\mathrm{CON}}$ at scales of 1-10 km, indicating that PWV $\mathrm{V}_{\text {SPD-H }}$ is more suitable for detecting water vapor fluctuations at the meso- $\gamma$ scale $(2-20 \mathrm{~km})$.

Figure 4 indicates spatial distributions of $\mathrm{PWV}_{\text {SPD-H }}$ over the Uji network during 0300-0430 LT at about every $30 \mathrm{~min}$. The PWV distribution is relatively homogeneous at 0300 LT. However, with time the distribution became increasingly complex, and a strong meridional gradient formed in which the PWV values in the north were higher than those in the south.

To investigate the horizontal scale of PWV variations, we analyzed the distance dependency of correlation coefficients of zenith wet delay (ZWD), that is, the vertically integrated signal delay by water vapor, of the Uji network. According to Askne and Nordius (1987), the ZWD is proportional to the PWV and the proportionality factor can be estimated from the surface temperature at the GNSS receiver (Bevis et al. 1992; Rocken et al. 1993). To eliminate the effect of errors derived from the conversion procedure from ZWD to PWV, we analyzed ZWD instead of PWV. Figure 5 shows the correlation coefficient of ZWD of the Uji network as a function of horizontal distance. The correlation coefficient was relatively high during 0600-0900 LT, the period when raining had ceased at Uji. On the other hand, when there was weak rain during 0000-0300 LT and heavy rain during 0300-0600 LT at $\mathrm{Uji}$, the correlation coefficients were smaller as the precipitation intensity became strong. This observational fact means that the characteristic length scale of water vapor variability became smaller, affected by convective activity. Fitted curves indicate that the e-folding scales, where e is Napier's constant, were $3.5 \mathrm{~km}$ during 0000 $0300 \mathrm{LT}$ and $1.9 \mathrm{~km}$ during 0300-0600 LT. This result is comparable to the result of Shoji et al. (2004), which analyzed the distance dependency of correlation coefficients of GNSS post-fit residuals and reported that the horizontal distance at which the correlation coefficients equaled $1 / e$ was about $2-3 \mathrm{~km}$.

\section{Design of the data assimilation experiment Assimilation system}

We used the LETKF assimilation method implemented in the JMA-NHM. The NHM-LETKF system used in this study was developed by Seko et al. (2013), in which mesoscale assimilation is conducted in the outer domain with a $15-\mathrm{km}$ mesh, and convective scale assimilation is conducted in the inner domain with a $1.875-\mathrm{km}$ mesh. The model domains were centered at $\mathrm{Uji}\left(135.8^{\circ} \mathrm{E}, 34.88^{\circ} \mathrm{N}\right)$ on a Lambert conformal projection with horizontal grid points of $80 \times 80$ and $120 \times 120$ for outer and inner 

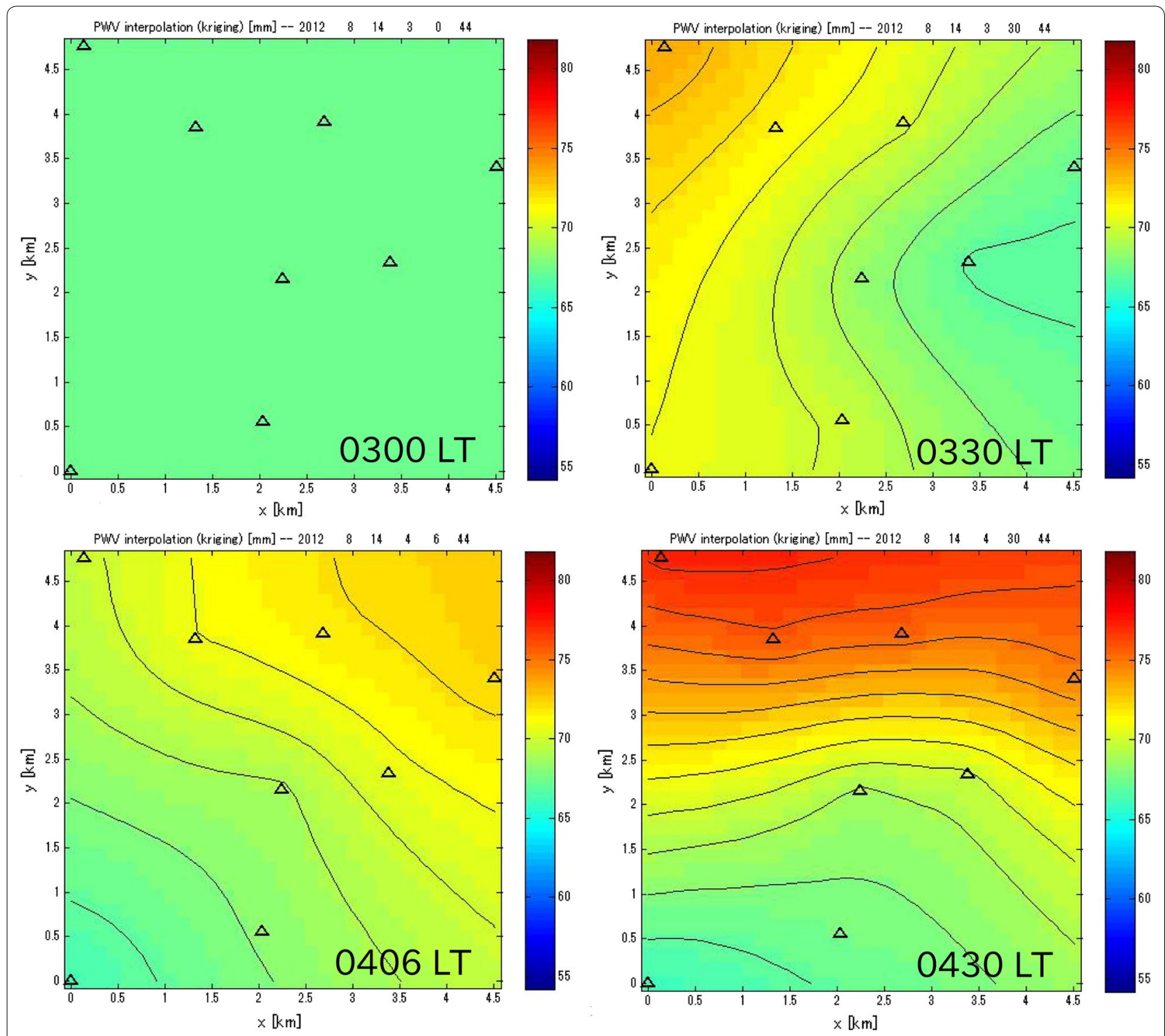

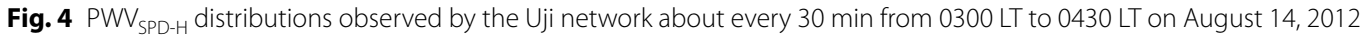

domains, respectively. We used a hybrid terrain-following coordinate system with 50 layers and a model top of $22.6 \mathrm{~km}$. The depth of the layers increased from $40 \mathrm{~m}$ to $886 \mathrm{~m}$ as their height increased. In the outer domain, the Kain-Fritsch cumulus parameterization scheme (Kain and Fritsch 1993) was used. In the inner domain, we employed bulk cloud physics, which predicts the mixing ratios of cloud, rain, ice crystals, and graupel without a cumulus parameterization scheme.

Figure 6 shows the flowchart of the data assimilation experiment. The number of ensemble members was 40 in both cases. For the first cycle, the initial conditions of the outer domain were derived from a JMA mesoscale analysis every $6 \mathrm{~h}$ from 1500 LT on August 1, 2012, to 0900 LT on August 11, 2012. The outer LETKF cycle was repeated from $0900 \mathrm{LT}$ on August 11, 2012, until 0900 LT on August 14, 2012, with a 6-h assimilation window. Observed data were assimilated every $1 \mathrm{~h}$. Lateral boundary conditions were derived from the JMA mesoscale analysis every $6 \mathrm{~h}$ from $1500 \mathrm{LT}$ on August 11, 2012, to 0900 LT on August 14, 2012. In the inner domain, the initial conditions in the first cycle and hourly boundary conditions were derived from the ensemble simulation results of the outer domain. The assimilation window was $1 \mathrm{~h}$, and observation data were assimilated every $10 \mathrm{~min}$. Nine cycles were conducted from 2100 LT on August 13, 


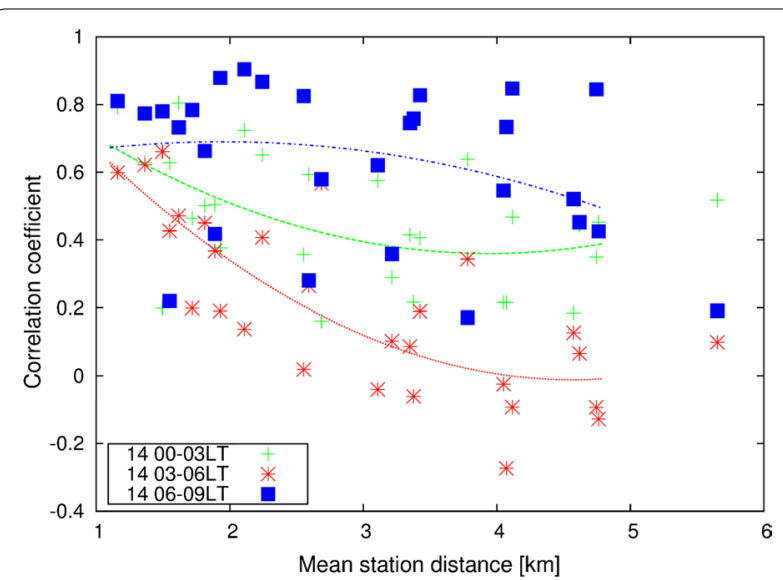

Fig. 5 Horizontal distance dependency of correlation coefficient of ZWD within the Uji network. The ZWD was converted from the SPD with the GNSS satellite at the highest elevation angle. Observational periods during 0000-0300 LT (green), 0300-0600 LT (red), and 0600-0900 LT (blue) on August 14, 2012, corresponded to weak rain, heavy rain, and no rain periods at RISH, respectively. Curves are fitted second-degree polynomials

2012, to 0600 LT on August 14, 2012. Surface and upper air sounding data used in the operational analysis at JMA, i.e., upper air sounding data (horizontal wind, temperature, and relative humidity), aircraft data (horizontal wind and temperature), wind profiler data (horizontal winds), ship and buoy data (pressure), and surface station data (pressure), were assimilated in both outer and inner domains. PWV data derived from the Uji network and nearby GEONET were assimilated only in the inner domain.

\section{Assimilation method of PWV}

It is not easy to assimilate PWV by using LETKF because analysis is independently performed at each model grid point in LETKF, while PWV is not a local variable. One of the methods is to assimilate PWV as observation data at the surface where water vapor amount is large. This method modifies water vapor amount mainly near the surface by using the vertical localization because the sampling error in the background error correlation between PWV and water vapor amount generally becomes larger as the layer of the model is distant from the surface. However, we needed to modify the water vapor amount of the model also at the middle troposphere because Uji was located at the south side of a stationary front and the middle troposphere was very humid during the Uji heavy rainfall event. Therefore, in this paper, we used the assimilation method of PWV proposed by Seko et al. (2011) which retrieves relative humidity $(\mathrm{RH})$ at the all layers of the model above a GNSS station before conducting the LETKF analysis. This method retrieves a RH profile above a GNSS station by modifying $\mathrm{RH}$ of the first-guess ensemble mean of the LETKF, considering the ensemble spread of RH and the correlation between PWV and water vapor amount estimated from the ensemble perturbations. Those intermediate profiles of $\mathrm{RH}$ were assimilated by LETKF. The procedure to produce the intermediate profile is as follows: (1) calculate the ensemble mean relative humidity $\left(\mathrm{RH}_{\text {mean }}(k)\right)$, mixing ratio $\left(Q_{\text {mean }}(k)\right)$, density $\left(\rho_{\text {mean }}(k)\right)$, and ensemble spread of relative humidity $\left(\mathrm{RH}_{\text {spread }}(k)\right)$ at the position of GNSS receivers; (2) estimate the correlation coefficient $(\operatorname{Corr}(k))$ between PWV and water vapor amount by using first-guess ensembles; and (3) modify the first-guess relative humidity using the following equations:

$$
\begin{aligned}
\mathrm{RH}_{\text {mod }}(k)= & \mathrm{RH}_{\text {mean }}(k)+\alpha \times \mathrm{RH}_{\text {spread }}(k) \\
& \times \operatorname{Corr}(k) \quad(k=1, \ldots, 50)
\end{aligned}
$$

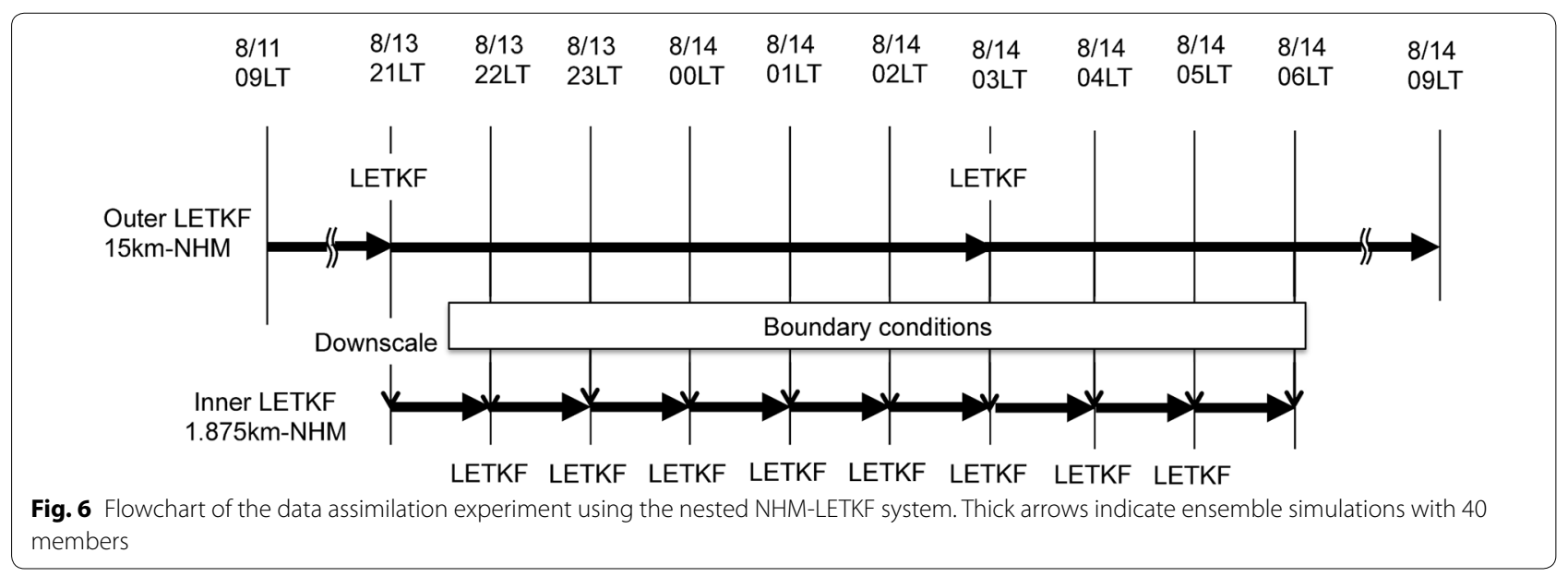




$$
\begin{aligned}
\mathrm{PWV}_{\text {mod }}= & \sum_{k=1}^{50} \frac{\mathrm{RH}_{\text {mod }}(k)}{\mathrm{RH}_{\text {mean }}(k)} \times Q_{\text {mean }}(k) \\
& \times \rho_{\text {mean }}(k) \times \mathrm{d} z
\end{aligned}
$$

where $\mathrm{RH}_{\text {mod }}(k), \mathrm{PWV}_{\text {mod }}$, and $\mathrm{d} z$ are the modified relative humidity, modified PWV, and thickness of layers, respectively. The coefficient $\alpha$ is determined so that $\mathrm{PWV}_{\text {mod }}$ has the same PWV value as the observation. Considering the height difference between the real and model ground altitude at the position of the GNSS receivers, we calculated the product between the water vapor amount at the lowest layer and the altitude difference, and we added or subtracted it from the observed PWV data. This modification to the observed PWV data can be applicable only when the height difference between the real and model ground altitude at the position of the GNSS receivers is small. Therefore, PWV data were not assimilated when height differences between the real and model ground altitude exceeded $50 \mathrm{~m}$. Locations of the eliminated stations for this reason are indicated in Fig. 1a. PWV data were also not assimilated when the PWV difference between the model and observation was larger than $5 \mathrm{~mm}$. For the GNSS stations shown in Fig. 1b, both $\mathrm{PWV}_{\mathrm{CON}}$ and $\mathrm{PWV}_{\mathrm{SPD}-\mathrm{H}}$ were used for data assimilation, while, for other GEONET stations not included in Fig. 1b, only $\mathrm{PWV}_{\mathrm{CON}}$ was used for data assimilation.

\section{Settings of localizations}

As noted in earlier studies (Houtekamer and Mitchell 1998; Hamil et al. 2001), covariance localization is needed in the ensemble Kalman filter to handle the problem of sampling errors due to the limited ensemble member size. In the LETKF, an observation localization is adopted such that the inverse of the localization function is multiplied by the observation error covariance (Hunt et al. 2007, Miyoshi et al. 2007). The localization function used in this study was the following Gaussian function:

$$
w(r)=\exp \left(-\frac{r^{2}}{2 \sigma^{2}}\right),
$$

where $\sigma$ is the parameter that determines the localization scale and $r$ indicates the physical distance between the analysis grid point and the observation point. Because this function does not go to zero, the covariance values were forced to equal zero outside the following localization radius:

$$
r=2 \sqrt{\frac{10}{3}} \sigma
$$

That is, only the observed data inside a circle with radius $r$ are assimilated. The $\sigma$ values of five grids in the horizontal direction and three layers in the vertical direction were used in the previous study, which corresponded to a horizontal localization radius of $34.2 \mathrm{~km}$ in the inner LETKF. The vertical error correlation of relative humidity is generally large over a rainfall region. To reduce the vertical error correlation of the assimilation data, we thinned out the retrieved humidity data every four layers. In addition, we set the vertical localization parameter " $\sigma$ " equal to the length of one layer.

In the conventional setting of the NHM-LETKF, a single horizontal localization radius of $34.2 \mathrm{~km}$ was used. However, this radius is larger than the horizontal scale of convection, i.e., a few $\mathrm{km}$, and scale of background error correlation of PWV around convection. When the ensemble simulation reproduces observed precipitation, assimilation of PWV observed in the precipitation area makes the simulation accuracy worse at distant grids from the observation site. This is because of sampling errors due to limited ensemble size. In contrast, when the ensemble simulation does not reproduce observed precipitation, a wide area around the GNSS receiver is incorrectly moistened by assimilating PWV with the large localization radius. To deal with these problems, we make the localization radius smaller when precipitation is observed. Figure 7 shows the background error correlation of PWV derived from a numerical model as a function of the horizontal distance. The model-derived PWV values were calculated by vertically integrating the products of the density and water vapor mixing ratio at each model layer. The error correlations were analyzed using a 500-m mesh ensemble dataset with 40 members. Correlation scales were analyzed for a rain-free area, weak

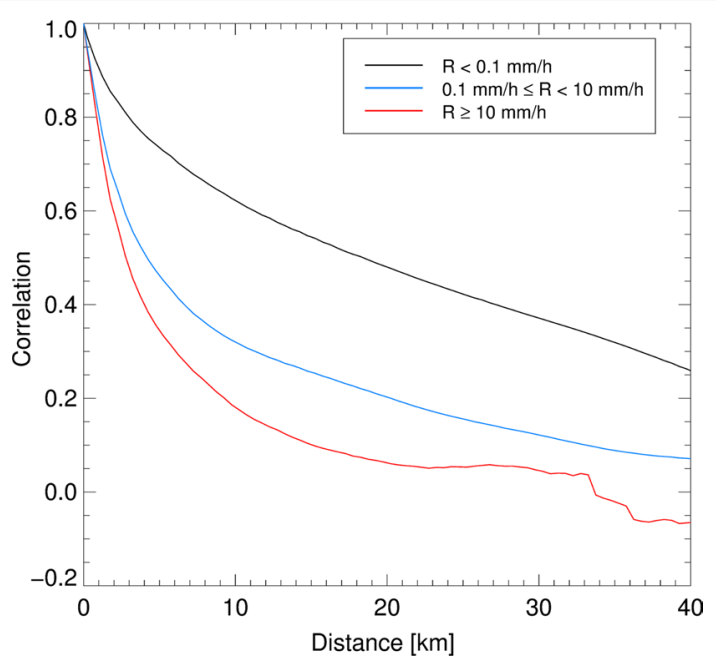

Fig. 7 Horizontal distance dependency of error correlation of PWV. Black, blue, and red colors indicate correlation coefficients at rain-free, weak rain, and heavy rainfall areas, respectively 
rain area, and heavy rain area, by dividing the rain rates $(R[\mathrm{~mm} / \mathrm{h}])$ into the three intensity levels, i.e., $R<0.1$, $0.1 \leq R<10$, and $R \geq 10$. The e-folding scales for the correlations were $30.8,7.5$, and $4.8 \mathrm{~km}$ for the rain-free, weak rain, and heavy rain areas, respectively. This result suggests that if we use the localization radius of $34.2 \mathrm{~km}$, the assimilation of PWV observed in the precipitating region introduces analysis errors because of the effects of spurious error correlations that were not eliminated by the large localization. Therefore, we investigate whether the simulation accuracy can be improved by using smaller localization radii to assimilate $\mathrm{RH}_{\text {mod }}$ data converted from GNSS-derived PWV over the precipitating region. Although increasing the ensemble size or model resolution is effective alternative methods to estimate the appropriate background error covariance, we fixed the ensemble size and model resolution in order to evaluate the effects of using small localization radii. We adopted

Table 1 Setting of localization radii for SLOC

\begin{tabular}{lc}
\hline Rain rate $(\boldsymbol{R})(\mathbf{m m} / \mathbf{h})$ & Localization radius $\mathbf{( k m )}$ \\
\hline$R>10$ & 4.8 \\
$0.1<R<10$ & 7.5 \\
$R<0.1$ & 30.8 \\
\hline
\end{tabular}

multiple horizontal localization radii, depending on the rain rates observed by weather radar. This multi-localization setting is called "SLOC," hereinafter (Table 1), while the experiment using the single localization of $34.2 \mathrm{~km}$ is named "CNTL." Figure 8 shows a flowchart showing how to set the localization radii in the SLOC experiment. In the SLOC experiment, the horizontal localization radii on each grid point for assimilating $\mathrm{RH}_{\text {mod }}$ data converted from GNSS-derived PWV were determined by estimating the precipitation intensity at the analysis grid point from the interpolation of JMA weather radar data. The $\mathrm{RH}_{\text {mod }}$ data converted from GNSS-derived PWV were assimilated with the horizontal localization radius of SLOC only when the radar-derived precipitation intensity at the GNSS stations belonged to the same intensity level at the analysis grid point. Before conducting the LETKF analysis, we made a list file which wrote combinations of analysis grid $(i, j, k), \mathrm{RH}_{\text {mod }}$ data and its latitude/ longitude information, and localization radius " $r$." This file is read by LETKF program to change the localization radius to assimilate $\mathrm{RH}_{\text {mod }}$ data.

Experimental results were evaluated by the ensemble mean of the hourly accumulated rainfall amount in the inner domain, where the radar rainfall data of JMA were referenced. We analyzed the spatial average of the root-mean-square error (RMSE) in the enclosed area that included the MCS over the Uji network, i.e., the

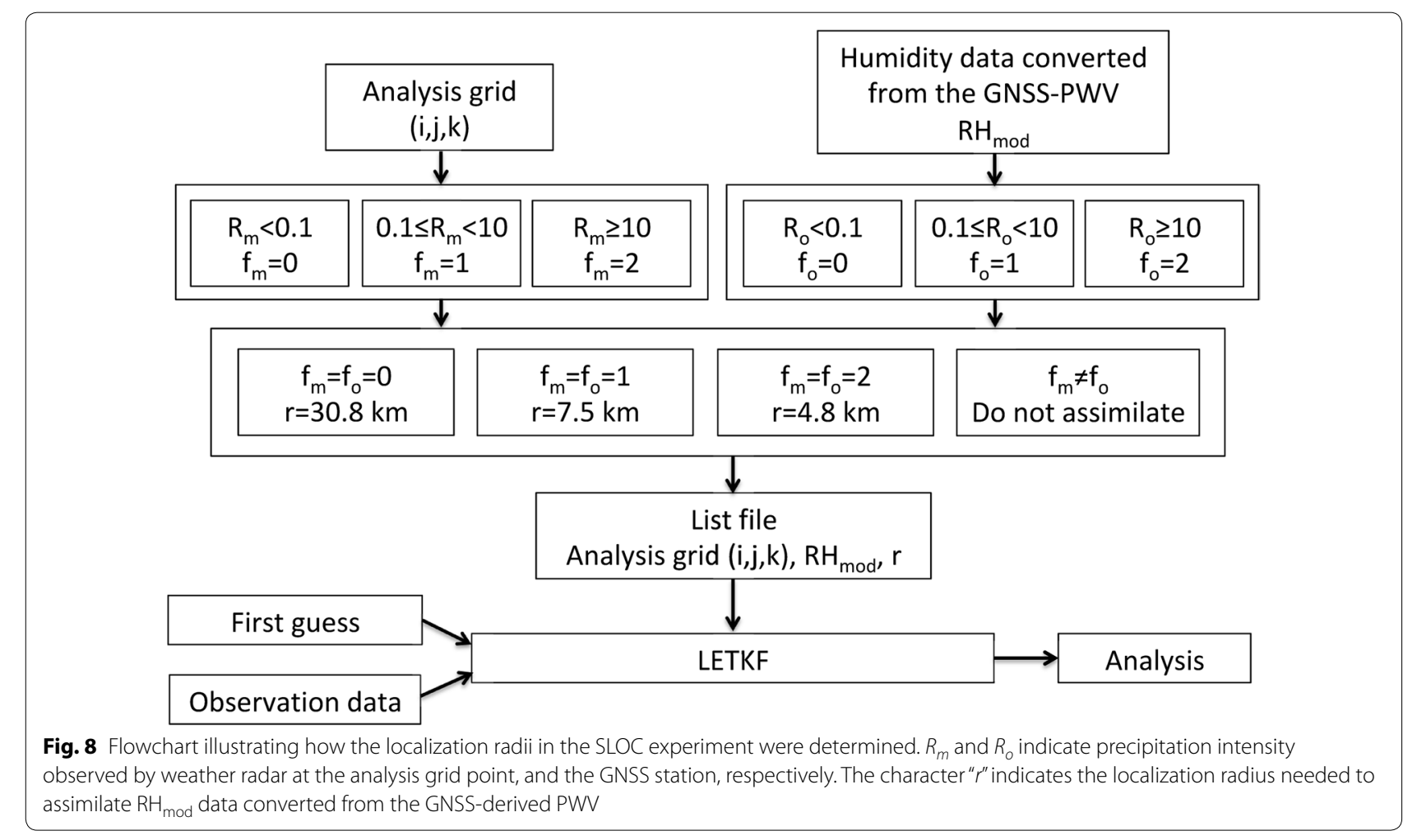




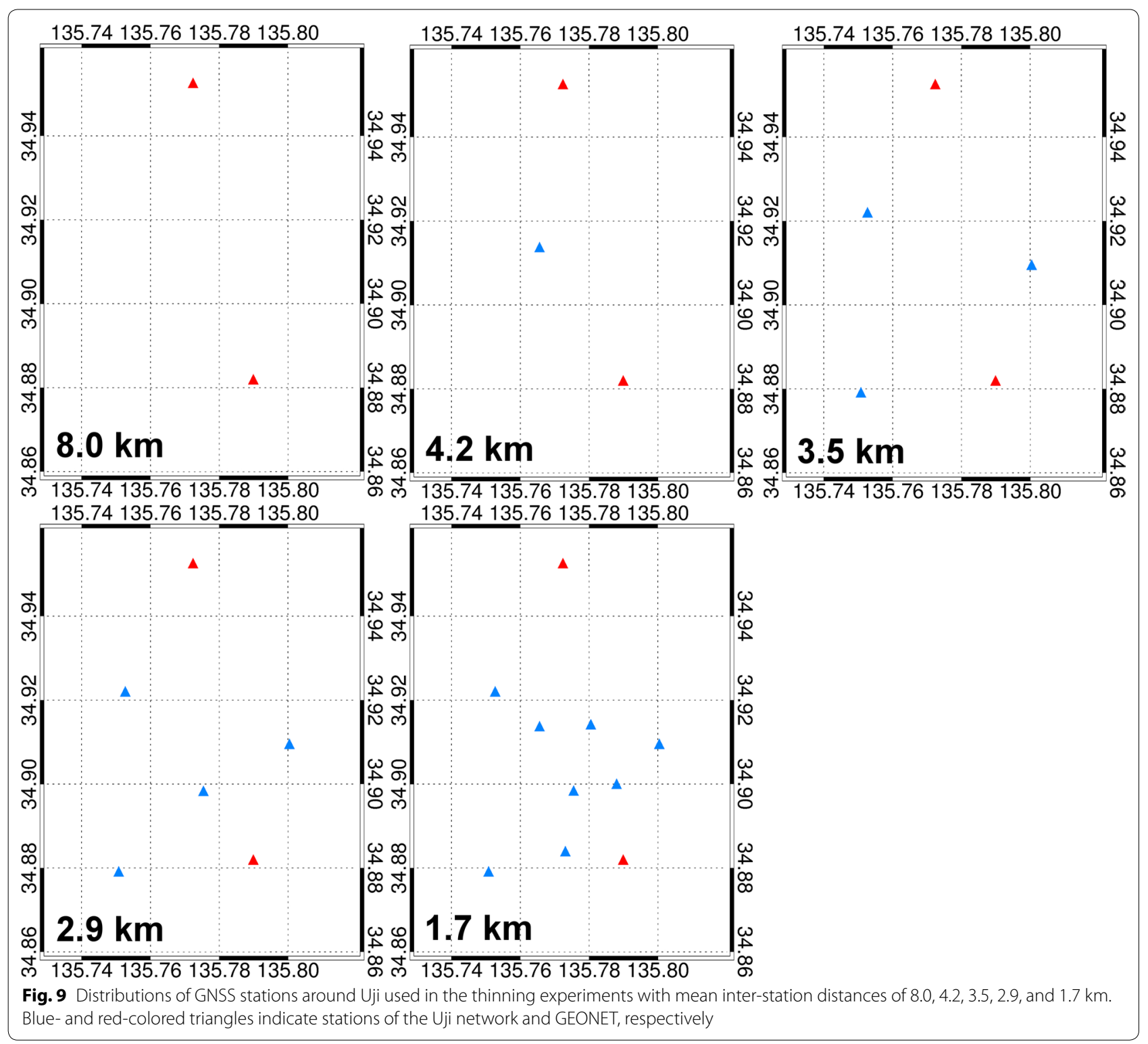

area delimited by the rectangle A shown in Fig. 1a. We calculated the improvement rates (IR) of RMSE using the equation below:

$$
\mathrm{IR}=\frac{\mathrm{RMSE}_{\mathrm{w} / \mathrm{o} P W V}-\mathrm{RMSE}_{\mathrm{w} / \mathrm{PWV}}}{\mathrm{RMSE}_{\mathrm{w} / \mathrm{o}} \mathrm{PWV}} \times 100,
$$

where "w/o PWV" indicates an experiment without assimilating PWV data. The sensitivity of the simulation accuracy of the MCS to the mean inter-station distance was investigated by thinning out the PWV data of the Uji network. Figure 9 shows the distribution of GNSS stations used in each thinning experiment. The code for each experiment and the settings of the thinning experiments are described in Table 2 . We aimed to clarify the following two effects by the experiments: (1) effect of using multi-localization scale to remove sampling errors and (2) the number of assimilated PWV (i.e., information content) and observation error correlation. We investigated the first issue by comparing CNTL8.0km and SLOC $8.0 \mathrm{~km}$ or CNTL3.5km and SLOC $3.5 \mathrm{~km}$. Next, we compared the results of five SLOC experiments to discuss a trade-off problem of the information content and observation error correlation.

\section{Results of the data assimilation experiment}

Figure 10 shows the mean RMSE of PWV at 0200, 0300, 0400 , and $0500 \mathrm{LT}$ on the 14th, analyzed by the inner LETKF. The RMSE values were calculated by using the 
Table 2 Code for each experiment and the settings of the thinning experiments

\begin{tabular}{lll}
\hline & Localization & Mean station distance $\mathbf{( k m )}$ \\
\hline CNTL8.0km & CNTL & 8.0 \\
CNTL3.5km & CNTL & 3.5 \\
SLOC8.0km & SLOC & 8.0 \\
SLOC $4.2 \mathrm{~km}$ & SLOC & 4.2 \\
SLOC $3.5 \mathrm{~km}$ & SLOC & 3.5 \\
SLOC2.9km & SLOC & 2.9 \\
SLOC1.7km & SLOC & 1.7 \\
\hline
\end{tabular}

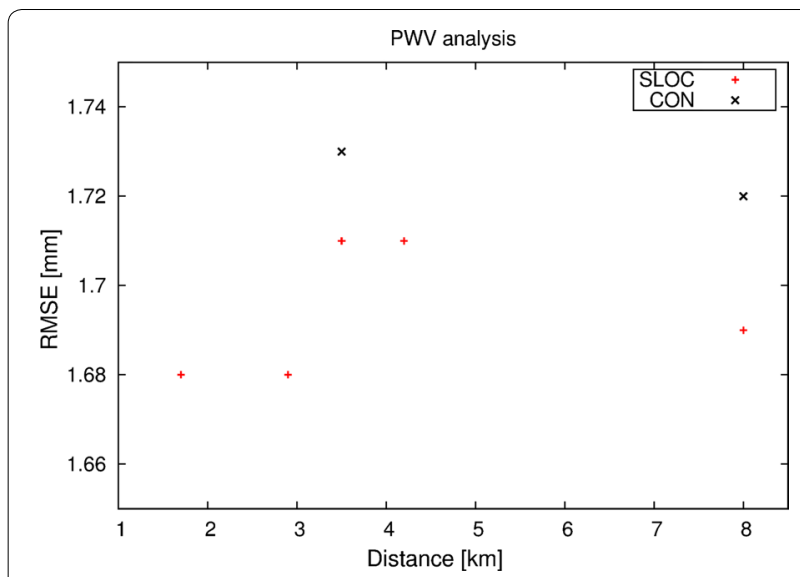

Fig. 10 RMSE of PWV analyzed by the inner LETKF. RMS values are averaged during 0200-0600 LT on August 14, 2012. Experiments indicated by the plus symbols are assimilated PWV $\mathrm{SPD}-\mathrm{H}_{\mathrm{H}}$ with the SLOC localization setting. Experiments indicated by the cross symbols are

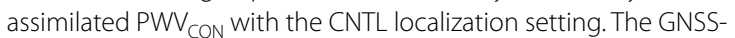

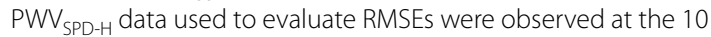
stations shown in Fig. 1b, which are the same data assimilated in the SLOC experiment with the mean inter-station distance of $1.7 \mathrm{~km}$

GNSS-derived PWV data observed at the ten GNSS stations in Fig. 1b. RMSEs of the analyzed PWV of the SLOC experiments were smaller than those of the CNTL experiments. This result suggests that small horizontal localization radii are needed to reproduce small-scale, i.e., less than $10 \mathrm{~km}, \mathrm{PWV}$ distributions by ensemble data assimilation. In the SLOC experiments, the RMSE of the analyzed PWV was smallest when the horizontal resolution of the assimilated PWV data was 2.9 and $1.7 \mathrm{~km}$. Figure 11 shows the horizontal distribution of the analysis increment of PWV for each SLOC experiment, which assimilated PWV $\mathrm{V}_{\text {SPD-H }}$ data at $0500 \mathrm{LT}$ on the 14th. At this moment, a strong meridional gradient of PWV formed over the Uji network (Fig. 4). The observed meridional gradient of PWV was not well reflected in the analysis increment of the PWV of the SLOC $8.0 \mathrm{~km}$ experiment in which only GEONET-PWV data were assimilated. In contrast, the observed meridional gradient of PWV was well reflected in the analysis increment of PWV when the horizontal resolutions of the assimilated PWV data were $3.5,2.9$, and $1.7 \mathrm{~km}$.

We show in Fig. 12 the assimilation effects of highresolution PWV on the simulation accuracy of the hourly rainfall amount. In the experiments in which the horizontal resolution of the assimilated PWV data was $8.0 \mathrm{~km}$ around $\mathrm{Uji}$, the simulation accuracy of the SLOC experiment was better than that of CNTL. This is because we eliminated the spurious error correlations of PWV between distant locations by applying the small localization radii over the precipitating region. This result suggests that the horizontal localization scale in the precipitating region should be smaller than that in the non-precipitating region when we assimilate the GEONET-derived PWV data. In the "CNTL" experiment, the simulation accuracy of the hourly rainfall amount was degraded when the mean inter-station distance of the assimilated PWV around Uji was decreased from 8.0 to $3.5 \mathrm{~km}$. In the nested NHM-LETKF, data assimilation is conducted on the assumption that observation data are uncorrelated. The simulation accuracy of the CNTL experiment decreased when the horizontal spacing of assimilated PWV data was $3.5 \mathrm{~km}$ probably because the assimilated PWV data around Uji were correlated. In contrast, in the "SLOC" experiment, the simulation accuracy was most improved when the inter-station distance of the PWV data around Uji was $3.5 \mathrm{~km}$. We inferred that the influence of the observation error correlation of PWV was small because the number of PWV data used in the LETKF analysis in each grid point was decreased with the use of the small horizontal localization radii. Two kinds of "SLOC" experiments were conducted here (Fig. 12) assimilation of $\mathrm{PWV}_{\mathrm{CON}}$ (black) and $\mathrm{PWV}$ SPD-H (red). In all thinning experiments, the results of assimilating PWV $\mathrm{V}_{\text {SPD-H }}$ were better than the results of assimilating $P W V_{\mathrm{CON}}$. As already explained in section "GNSS-derived PWV observed by the Uji network", PWV $\mathrm{CON}_{\text {in }}$ istimated as a spatially averaged water vapor amount within an inverse cone defined by the low elevation cutoff angle. Therefore, $\mathrm{PWV}_{\mathrm{CON}}$ at each GNSS stations of the Uji network observed same portions of the atmosphere, probably having larger observation error correlation than $\mathrm{PWV}_{\mathrm{SPD}-\mathrm{H}}$ data. We inferred that the results of the SLOC experiments assimilating $\mathrm{PWV}_{\mathrm{SPD}-\mathrm{H}}$ were better than those of assimilating PWV $\mathrm{CON}_{\mathrm{CO}}$ because the observation error correlation of PWV $\mathrm{VPD}_{\mathrm{SP}}$ was smaller than that of $P W V_{C O N}$. However, quantitative examination about the observation error correlation of PWV should be investigated in future study.

Figure 13a shows horizontal distribution of 1-h rainfall amount at $0600 \mathrm{LT}$ on 14 simulated by $\mathrm{SLOC} 3.5 \mathrm{~km}$, 

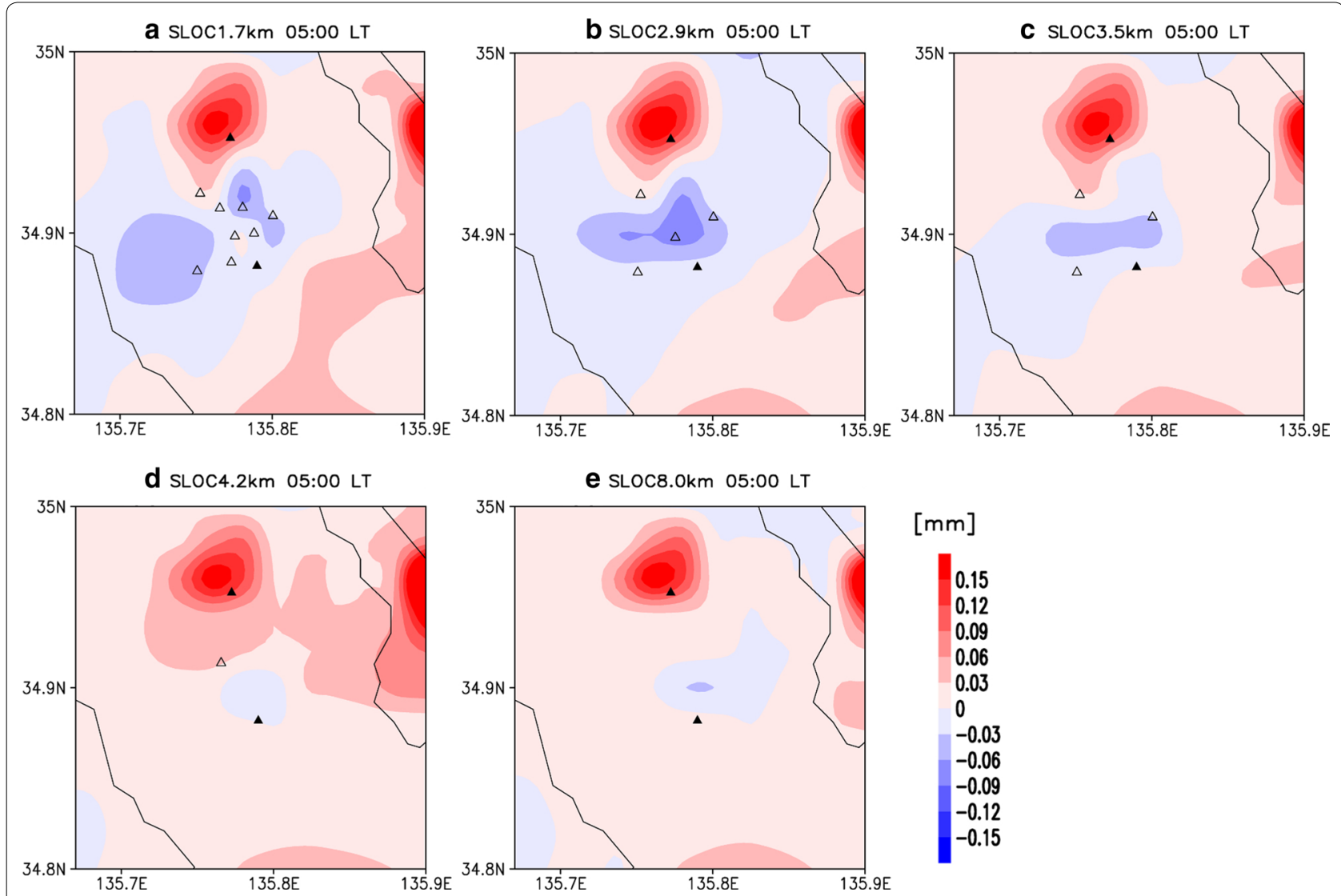

Fig. 11 Distributions of the analysis increment of PWV at 0500 LT on August 14, 2012, analyzed by the SLOC experiments that assimilated PWV at the stations indicated by triangle symbols. Open triangles and filled triangles indicate stations of the Uji network and GEONET, respectively

and Fig. 13b shows horizontal distributions of difference of 1-h rainfall amount between SLOC3.5km and CNTL8.0km. Rainfall amount simulated by SLOC $3.5 \mathrm{~km}$ increased compared to that of CNTL8.0km along the northern side of the MCS where the Uji network was located (Fig. 13b). In contrast, rainfall amount simulated by SLOC3.5km decreased at the southern side of the MCS. It was found that simulation accuracy mainly improved at the leeward side of the Uji network.

\section{Summary and discussion}

We first investigated the characteristic length scale of water vapor variability observed by the Uji GNSS network. The e-folding distance of the correlation coefficients of the observed ZWD was 1.9-3.5 km when precipitation was observed around the network. We also analyzed the scale of the background error correlations of PWV by using $500-\mathrm{m}$ mesh ensemble data with 40 members. Correlation scales were analyzed for rain-free areas, weak rain areas, and heavy rain areas by dividing the rain rates $(R[\mathrm{~mm} / \mathrm{h}])$ into three intensity levels, i.e., $R<0.1,0.1 \leq R<10, R \geq 10$. It was found that the e-folding scales of correlations were $30.8,7.5$, and $4.8 \mathrm{~km}$ for the rain-free, weak rain, and heavy rain areas, respectively. Therefore, a smaller horizontal localization radius is recommended to assimilate PWV data over the precipitating regions.

Using the nested NHM-LETKF system, we conducted an assimilation experiment of high-resolution PWV data from the Uji network. Although a single localization radius of $34.2 \mathrm{~km}$ was used in the earlier conventional LETKF experiment, we applied small localization radii, depending on the rain rates $(\mathrm{R}[\mathrm{mm} / \mathrm{h}])$ observed by weather radar, i.e., $30.8 \mathrm{~km}(R<0.1), 7.5 \mathrm{~km}(0.1 \leq R<10)$, and $4.8 \mathrm{~km}(R \geq 10)$. By using multiple localization radii over the rainfall area, the accuracy of both PWV analyzed by LETKF and the simulation results of the hourly rainfall was improved. The result was improved because we eliminated the spurious error correlations of PWV between distant locations by applying small localization radii over the precipitating region. The use of small localization radii was also effective in reducing the influence of observation error correlation of PWV around the hyper-dense GNSS receiver network. 


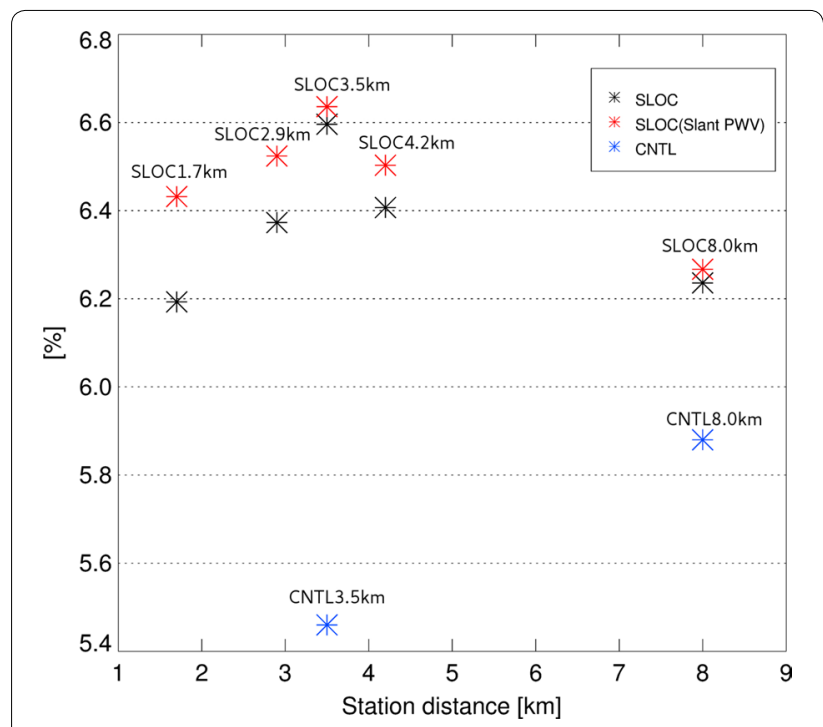

Fig. 12 Improvement rates of RMSE of hourly rainfall amount simulated by the inner domain model as a function of the interstation distances of the assimilated PWV data. To calculate the mean improvements of RMSE, we used the ensemble mean data of each inner model cycle during 0200-0600 LT on August 14, 2012, i.e., four samples. Red-and black-colored symbols indicate that assimilated PWV data around Uji shown in Fig. $1 \mathrm{~b}$ were PWV $\mathrm{SPD}_{\mathrm{H}}$ and $\mathrm{PWV}_{\text {CON }}$ respectively, using the SLOC localization setting. The blue-colored symbol indicates that assimilated PWV data were all $\mathrm{PWV}_{\mathrm{CON}}$, using CNTL localization setting
Miyoshi et al. (2014) conducted 10,240-member LETKF with an intermediate atmospheric global circulation model (AGCM) and revealed meaningful long-range error correlations at continental scales. Kunii (2014) investigated the influence of sampling noise on the background error covariance by using 1000-member ensemble forecasting with the JMA-NHM. It was reported that an ensemble size of 500 would be large enough to approximate the error covariance under the configuration with a horizontal resolution of $15 \mathrm{~km}$. We adopted an ensemble size of 40 , so localization was needed for such a small ensemble size. Using multiple localization scales, we tried to solve the problem of sampling errors in the background error covariance. A grid size of less than a few $\mathrm{km}$ was needed to capture the structure of the convective scale background error covariance. In this study, we set the grid size to $1.875 \mathrm{~km}$ to reproduce the heavy rainfall.

In the assimilation experiment, we used PWV data that were converted from slant delay data at the highest elevation angle. This conversion procedure may introduce additional observational errors, so we consider that the direct assimilation of SWV or SPD (e.g., Kawabata et al. 2013) is preferable to get more accurate analysis results. However, it is computationally expensive to assimilate SWV directly in the SLOC experiments because we need

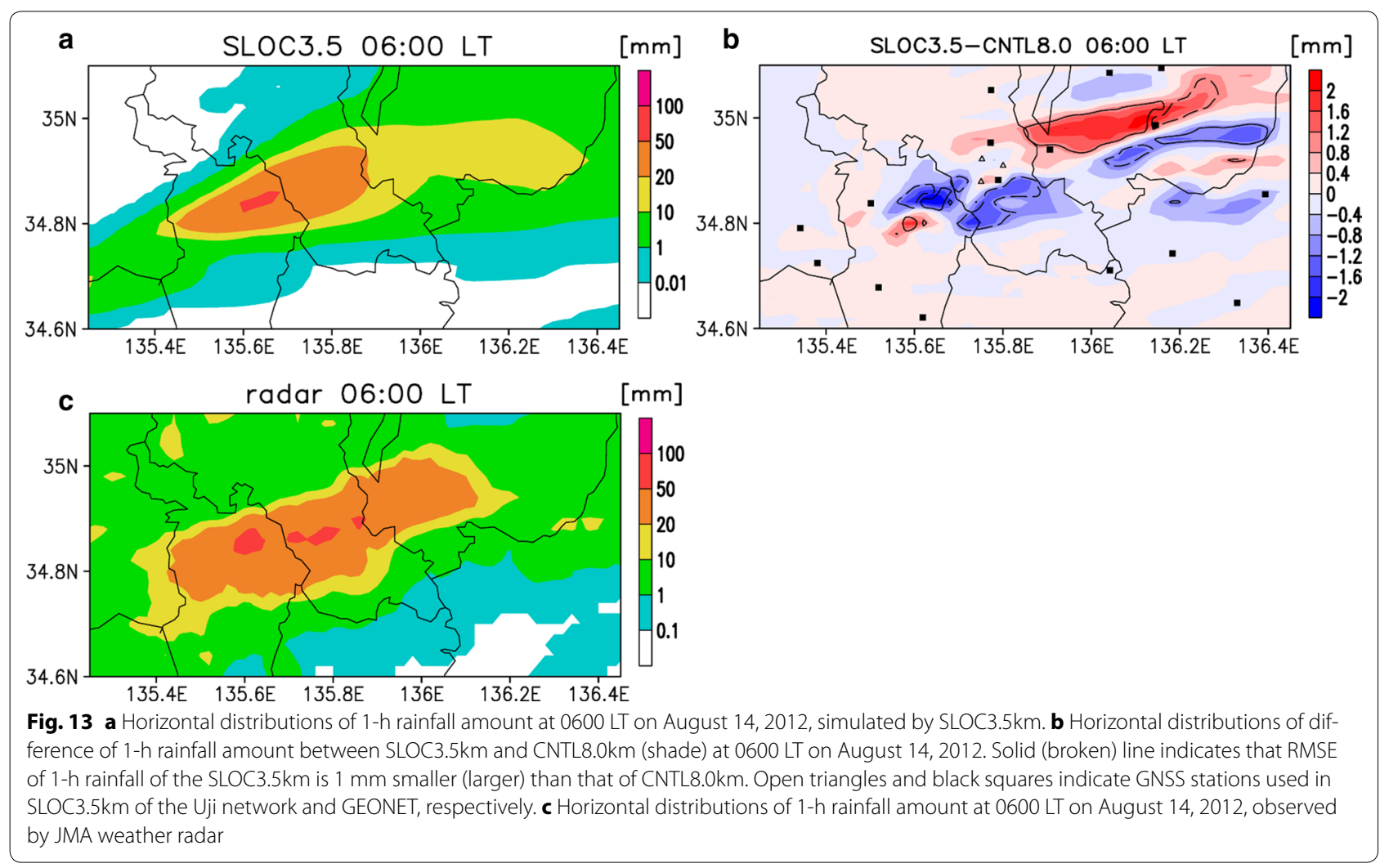


to estimate the precipitation intensity at each point where the slant paths of the SWV intersect each model layer and apply different localization scales for each point. Therefore, we converted SWV at the highest elevation angle into PWV $\mathrm{V}_{\mathrm{SPD}-\mathrm{H}}$ to shorten the time for determining whether the assimilated relative humidity converted from GNSS water vapor data existed in the rainfall area or not. During the Uji heavy rainfall event on August 13-14, 2012, the QZSS satellite did not exist at a high elevation angle. Therefore, we used GPS satellites above $60^{\circ}$ elevation angles to estimate the PWV distribution within the Uji network. The error due to the mapping will be greatly reduced when the satellite constellation of the four QZSS is completed, and at least one QZSS satellite remains near the zenith. Shoji et al. $(2014,2015)$ showed that the error of PWV $\mathrm{SPD-H}_{\mathrm{S}}$ derived from mapping reaches its minimum at the location where the line of sight reaches the scale height of water vapor. Assimilating the PWVV $\mathrm{V}_{\mathrm{SPD}-\mathrm{H}}$ data as PWV just over the location where the line of sight reaches the scale height of water vapor is recommended.

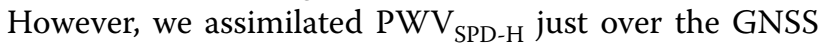
stations because the elevation angles were greater than $60^{\circ}$.

The thinning experiments showed that in the case of the Uji heavy rainfall event, the simulation accuracy was most improved when the mean inter-station distance around Uji was $3.5 \mathrm{~km}$. This result is consistent with the observed characteristic length scale of ZWD (1.9$3.5 \mathrm{~km}$ ) during the rainfall, suggesting that the optimum spatial resolution of the PWV measurement is related to the characteristic length scale of water vapor variability.

By using the PWV data observed by the hyper-dense GNSS receiver network, the present case study demonstrated that the characteristic length scale of water vapor variability changed significantly depending on precipitation intensity. It is important to consider the scales of the variability of water vapor to improve the simulation accuracy when PWV is assimilated.

\footnotetext{
Abbreviations

GNSS: Global navigation satellite system; GEONET: GNSS Earth Observation Network; GSI: Geospatial Information Authority of Japan; JMA: Japan Meteorological Agency; LETKF: Local ensemble transform Kalman filter; MCS: Mesoscale convective system; NHM: Non-hydrostatic model; PWV: Precipitable water vapor; QZSS: Quasi-Zenith Satellite System; RISH: Research Institute for Sustainable Humanosphere; RMS: Root-mean-square; RMSE: Root-meansquare error; SPD: Slant path delay; SWV: Slant water vapor; ZTD: Zenith tropospheric delay; ZWD: Zenith wet delay.

Authors' contributions

MO performed assimilation experiment and data analysis. TT guided the research direction and provided insights and interpretation. HS developed the nested NHM-LETKF system and assimilation method of PWV and provided interpretations. YS processed the GEONET-derived PWV data and provided interpretations. ER processed the high-resolution water vapor data derived from the hyper-dense GNSS receiver network in Uji. All authors read and approved the final manuscript.
}

\section{Authors' information}

TT works at Research Organization of Information and Systems (ROIS), Tokyo, Japan. HS and YS are researchers at Meteorological Research Institute (MRI), Japan Meteorological Agency (JMA), Tsukuba, Japan. ER works at Geomatics Research \& Development (GReD), Como, Italy. MO was a Ph.D. student at the Research Institute for Sustainable Humanosphere (RISH), Kyoto University, Japan, and now works at Observation Department of JMA, Tokyo, Japan.

\section{Author details \\ ${ }^{1}$ Research Institute for Sustainable Humanosphere (RISH), Kyoto University, Gokasho, Uji, Kyoto 611-0011, Japan. ${ }^{2}$ Observation Department, Japan Meteorological Agency (JMA), 1-3-4 Otemachi, Chiyoda-ku, Tokyo 100-8122, Japan. ${ }^{3}$ Research Organization of Information and Systems (ROIS), 4-3-13, Toranomon, Minato-ku, Tokyo 105-0001, Japan. ${ }^{4}$ Meteorological Research Institute (MRI), Japan Meteorological Agency (JMA), 1-1 Nagamine, Tsukuba, Ibaraki 305-0052, Japan. ${ }^{5}$ Geomatics Research \& Development (GReD) srl, Via Cavour 2, 22074 Lomazzo, Como, Italy.}

\section{Acknowledgements}

GEONET data were provided by Geospatial Information Authority of Japan (GSI). This study is partly supported by JSPS KAKENHI Grant Numbers JP15H03724 and JP17H00852. In addition, this work is partly supported by JSPS Bilateral Open Partnership Joint Research Projects and a Grant-in-Aid for JSPS Fellow (JP13J57053). The JMA-NHM was provided by JMA. The initial and boundary data of JMA-NHM were provided by means of the "Meteorological Research Consortium," a framework for research cooperation of the JMA and Meteorological Society of Japan (MSJ). We appreciate Dr. Kazutoshi Sato of Japan Aerospace Exploration Agency (JAXA), for providing us water vapor data derived from the Uji network. We also thank Dr. Masanori Yabuki of RISH, Kyoto University, for his support in providing a computer server. Thanks are extended to Dr. Kazuo Saito and members of the second laboratory of the forecast research department of MRI for giving valuable comments.

\section{Competing interests}

The authors declare that they have no competing interests.

\section{Availability of data and materials}

GEONET data were provided by GSI. PWV data derived from the Uji network were provided by IUGONET, RISH. JMA mesoscale analysis was provided by JMA. Weather radar data were provided by JMA. Surface and upper air sounding data were provided by JMA.

\section{Ethics approval and consent to participate}

Not applicable.

\section{Funding}

This study is partly supported by JSPS KAKENHI Grant Numbers JP15H03724 and JP17H00852. This work is also partly supported by JSPS Bilateral Open Partnership Joint Research Projects and a Grant-in-Aid for JSPS Fellow (JP13J57053).

\section{Appendix}

Undifferenced GPS L1/L2 observations were processed by the precise point positioning (PPP) technique, using the RTNet software (http://gps-solutions.com/rtnet software). RTNet applies an extended Kalman filter to code and phase iono-free observations, with float phase ambiguities. The processing rate was set to $30 \mathrm{~s}$. Final orbits and 30-s satellite clock products published by the International GNSS service (IGS) were used. The elevation cutoff was set to 10 degrees. The global mapping function (GMF) (Böhm et al. 2006) was used to project the slant observations to the zenith direction, along which the zenith tropospheric delay (ZTD) parameter is estimated. All the corrections commonly used in PPP 
were applied, including the ocean loading displacements (FES2004 model) and satellite eclipses.

The time series of estimated ZTD were reduced to zenith wet delay (ZWD) by removing the zenith hydrostatic delay (ZHD) computed by means of the Saastamoinen model (Saastamoinen 1973). ZWD was then converted to PWV by using the Askne and Nordius formula (Askne and Nordius 1987), with the weighted mean temperature of the atmosphere modeled by the equations derived by Shoji (2010). The passage from ZTD to PWV was carried out using ground pressure and temperature measured by weather stations deployed within the dense network. It was possible to deploy a weather station only at half of the GNSS station sites in the dense network; pressure and temperature data for the remaining half were, thus, spatially interpolated by inverse distance weighting, taking into account their differences in height.

PWV derived from the Uji dense network by this procedure was extensively validated against radiosondes and microwave radiometers during the period in which the network was operating, yielding RMS differences of about $2 \mathrm{~mm}$.

By applying the technique first proposed by Shoji et al. (2004), Kačmařík et al. (2017) obtained results confirming that raw post-fit residuals should not be used to reconstruct slant delays as they might contain strong systematic effects, such as unmodeled phase center variations (e.g., multipath). In this study, we followed the same technique, i.e., we generated an azimuth/elevation map of post-fit phase residuals averaged over a sufficiently long time span (6 months) for each Uji network station site, to eliminate the systematic effects from the post-fit residuals. The map resolution was 3 degrees (azimuth) $\times 1$ degree (elevation). This map was used to correct the post-fit residuals obtained for each station, which were then used to reconstruct the slant delays. PWV data converted from a slant delay retrieved by this method were validated against radiosonde and higher accuracy was obtained than PWV retrieved by the standard GNSS meteorology technique (Sato et al. 2013). This previous study suggests that the post-fit residuals cleaned by the method used in this study actually contain small-scale water vapor information.

\section{Publisher's Note}

Springer Nature remains neutral with regard to jurisdictional claims in published maps and institutional affiliations.

Received: 3 September 2017 Accepted: 25 April 2018

Published online: 04 May 2018

\section{References}

Aonashi K (2008) Toward assimilation of MWR TBs into CRM: ensemble forecast error distribution and covariances of CRM variables and TBs. In: Proceedings of 2008 IEEE international geosciences and remote sensing symposium, TU2.210

Askne J, Nordius H (1987) Estimation of tropospheric delay for microwaves from surface weather data. Radio Sci 22(3):379-386

Bevis M, Businger S, Herring TA, Rocken C, Anthes RA, Ware RH (1992) GPS meteorology: remote sensing of atmospheric water vapor using the Global Positioning System. J Geophys Res 97(D14):15787-15801

Böhm J, Niell A, Tregoning P, Schuh H (2006) Global mapping function (GMF): a new empirical mapping function based on numerical weather model data. Geophys Res Lett 33(7):304

Evensen G (1994) Sequential data assimilation with a nonlinear quasi-geostrophic model using Monte Carlo methods to forecast error statistics. J Geophys Res 99(C5):10143-10162

Guo Y-R, Kuo Y-H, Dudhia J, Parsons DB, Rocken C (2000) Four-dimensional variational data assimilation of heterogeneous mesoscale observations for a strong convective case. Mon Weather Rev 128:619-643

Hamill TM, Whitaker JS, Snyder C (2001) Distance-dependent filtering of background error covariance estimates in an ensemble Kalman filter. Mon Weather Rev 129:2776-2790

Houtekamer PL, Mitchell HL (1998) Data assimilation using an ensemble Kalman filter technique. Mon Weather Rev 126:796-811

Hunt BR, Kostelich EJ, Szunyosh I (2007) Efficient data assimilation for spatiotemporal chaos: a local ensemble transform Kalman filter. Phys $D$ 230:112-126

Ishihara M, Takara K (2013) Organization of mesoscale convective systems causing heavy rainfall and flash flood around Uji, Kyoto on 14 August 2012. Ann Disas Prev Res Inst, Kyoto Univ 56(B):79-86

Kačmařík M, Douša J, Dick G, Zus F, Brenot H, Möller G, Pottiaux E, Kapłon J, Hordyniec P, Václavovic P, Morel L (2017) Inter-technique validation of tropospheric slant total delays. Atmos Meas Tech 10:2183-2208. https:// doi.org/10.5194/amt-10-2183-2017

Kain J, Fritsch J (1993) Convective parameterization for mesoscale models: the Kain-Fritsch scheme. The representation of cumulus convection in numerical models. Meteor Monogr 46:165-170

Kawabata T, Seko H, Saito K, Kuroda T, Tamiya K, Tsuyuki T, Honda T, Wakazki Y (2007) An assimilation and forecasting experiment of the Nerima heavy rainfall with a cloud-resolving 4-dimensional variational data assimilation system. J Meter Soc Jpn 85:255-276

Kawabata T, Shoji Y, Seko H, Saito K (2013) A numerical study on a mesoscale convective system over a subtropical island with 4D-Var assimilation of GPS slant total delays. J Meteor Soc Jpn 91:705-721

Kunii M (2014) The 1000-member ensemble Kalman filtering with the JMA nonhydrostatic mesoscale model on the K computer. J Meteor Soc Jpn 92(6):623-633

Kuo Y-H, Guo Y-R, Westwater ER (1993) Assimilation of precipitable water measurements into a mesoscale numerical model. Mon Weather Rev 121:1215-1238

Miyoshi T, Kondo K (2013) A multi-scale localization approach to an ensemble Kalman filter. SOLA 9:170-173

Miyoshi T, Yamane S, Enomoto T (2007) Localizing the error covariance by physical distances within a local ensemble transform Kalman filter (LETKF). SOLA 3:89-92

Miyoshi T, Kondo K, Imamura T (2014) The 10240-member ensemble Kalman filtering with an intermediate AGCM. Geophys Res Lett 41:5264-5271

Oigawa M, Realini E, Seko H, Tsuda T (2014) Numerical simulation on retrieval of meso- $\gamma$ scale precipitable water vapor distribution with the QuasiZenith Satellite System (QZSS). J Meteor Soc Jpn 92(3):189-205

Oigawa M, Realini E, Tsuda T (2015) Study of water vapor variations associated with meso- $\gamma$ scale convection: comparison between GNSS and nonhydrostatic model data. SOLA 11:27-30

Rocken C, Ware R, VanHove T, Solheim F, Alber C, Johnso J, Bevis M, Businger S (1993) Sensing atmospheric water vapor with the global positioning system. Geophys Res Lett 20(23):2631-2634

Saastamoinen J (1973) Contributions to the theory of atmospheric refraction. Bulletin G eod esique (1946-1975) 107(1):13-34 
Saito K, Ishida J, Aranami K, Hara T, Segawa T, Narita M, Honda Y (2007) Nonhydrostatic atmospheric models and operational development at JMA. J Meteor Soc Jpn 85B:271-304

Sato K, Realini E, Tsuda T, Oigawa M, Iwaki Y, Shoji Y, Seko H (2013) A highresolution, precipitable water vapor monitoring system using a dense network of GNSS receivers. J Disaster Res 8:37-47

Seko H, Kawabata T, Tsuyuki T, Nakamura H, Koizumi K, Iwabuchi T (2004) Impacts of GPS-derived water vapor and radial wind measured by Doppler radar on numerical prediction of precipitation. J Meteor Soc Jpn 82:473-489

Seko H, Miyoshi T, Shoji Y, Saito K (2011) Data assimilation experiments of precipitable water vapor using the LETKF system-an intense rainfall event over Japan 28 July 2008. Tellus 63A:402-412

Seko H, Tsuyuki T, Saito K, Miyoshi T (2013) Development of a two-way nestedLETKF system for cloud-resolving model. In: Park SK, Xu L (eds) Data assimilation for atmospheric, oceanic and hydrological applications, vol 2 Springer, Heidelberg, pp 489-507

Shoji Y (2010) Accurate estimation of precipitable water vapor using groundbased GPS observation network and its data assimilation into a mesoscale numerical weather prediction model. PhD thesis, Kyoto University

Shoji Y, Nakamura H, Iwabuchi T, Aonashi K, Seko H, Mishima K, Itagaki A, Ichikawa R, Ohtani R (2004) Tsukuba GPS dense net campaign observation: improvement in GPS analysis of slant path delay by stacking one-way postfit phase residuals. J Meteor Soc Jpn 82:301-314

Shoji Y, Kunii M, Saito K (2009) Assimilation of nationwide and global GPS PWV data for a heavy rain event on 28 July 2008 in Hokuriku and Kinki, Japan. SOLA 5:45-48

Shoji Y, Yamauchi H, Mashiko W, Sato E (2014) Estimation of local-scale precipitable water vapor distribution around each GNSS station using slant path delay. SOLA 10:29-33

Shoji Y, Mashiko W, Yamauchi H, Sato E (2015) Estimation of local-scale precipitable water vapor distribution around each GNSS station using slant path delay: evaluation of a severe tornado case using high-resolution NHM. SOLA 11:31-35

Yan X, Ducrocq V, Jaubert G, Brousseau P, Poli P, Champollion C, Flamant C, Boniface K (2009) The benefit of GPS zenith delay assimilation to highresolution quantitative precipitation forecasts: a case-study from COPS IOP 9. Q J R Meteorol Soc 135:1788-1800

Zhang F, Weng Y, Sippel JA, Meng Z, Bishop CH (2009) Cloud-resolving hurricane initialization and prediction through assimilation of Doppler radar observations with an ensemble Kalman filter. Mon Weather Rev 137:2105-2125

\section{Submit your manuscript to a SpringerOpen ${ }^{\circ}$ journal and benefit from:}

- Convenient online submission

$\checkmark$ Rigorous peer review

- Open access: articles freely available online

- High visibility within the field

- Retaining the copyright to your article

Submit your next manuscript at $\gg$ springeropen.com 